\title{
UPAYA MENINGKATKAN KEMAMPUAN GURU DALAM MEMANFAATKAN LINGKUNGAN SEKOLAH SEBAGAI SUMBER BELAJAR MELALUI KEGIATAN BUZZ GROUP
}

\section{DISCUSSION}

\author{
Erna Kusrini \\ SDN 2 Karangduren Pakisaji, Kabupaten Malang \\ ernakusrini70@gmail.com
}

\begin{abstract}
Abstrak
Dari hasil pantauan peneliti selaku Kepala Sekolah, selama ini para guru di SD Negeri 2 Karangduren Kecamatan Pakisaji masih jarang memanfaatkan lingkungan sekolah sebagai sumber belajar. Hasil kegiatan prasiklus menunjukkan bahwa semua guru belum memaksimalkan penggunaan lingkungan sekolah sebagai sumber belajar. Tujuan penelitian ini untuk memberikan penjelasan tentang pelaksanaan kegiatan buzz group discussion dan meningkatkan kemampuan guru dalam memanfaatkan lingkungan sekolah sebagai sumber belajar di SD Negeri 2 Karangduren Kecamaan Pakisaji. Penelitian ini adalah Penelitian Tindakan Sekolah (PTS) dan dilaksanakan dalam 2 siklus. Setiap siklus terdiri dari dua kali pertemuan. Subjek penelitian ini adalah seluruh guru kelas sejumlah 6 orang guru di SD Negeri 2 Karangduren Kecamatan Pakisaji. Instrumen pengumpulan data pada penelitian ini menggunakan lembar observasi yang terdiri dari lembar observasi diskusi, penilaian skenario pembelajaran dan pelaksanaan kegiatan pembelajaran. Hasil observasi pada kegiatan diskusi terdapat peningkatan sebesar 65,17 menjadi 79,50 pada siklus I dan 88,50 pada siklus terakhir. Pada penilaian skenario pembelajaran terdapat peningkatan sebesar 62,50 menjadi 80,00 pada siklus I dan 88,33 pada siklus terakhir. Pada penilaian pelaksanaan pembelajaran peningkatan sebesar 60,50 menjadi 80,00 pada siklus I dan 87,22 pada siklus terakhir. Berdasarkan hasil observasi dapat ditarik kesimpulan bahwa pelaksanaan pembinaan dengan metode bimbingan diskusi kelompok kecil atau (buzz group discusion) terbukti mampu meningkatkan kemampuan guru-guru di SD Negeri 2 Karangduren dalam menggunakan dan memanfaatkan lingkungan sekitar sebagai sumber belajar peserta didiknya.
\end{abstract}

Kata Kunci: sumber belajar, buzz groud discussion

\begin{abstract}
Based on researcher's general school scan, teacher at elementary school 2 Karangduren Pakisaji district still seldom use the school environmet as a learning source. The result of prasiklus shosw at all teachers have not made the most of school's use of the environment as a learning source. The study was called into question about carrying out the buzz group discussion environment as a study source at elementary school 2 Karangduren. This research is the study of school action and performed in 2 cycles. Each cycle of self-service from this two-time research facility. Subject of this research is all the teachers of thr first class of six teachers at elementary school 2 Karangduren pakisaji district. Data collection instrumen of this study use observation sheet made up of discussion observation sheet, the learning scenarion assessments and the performance af learning activities. Observing the discussion activity, the is an increas of 65.17 to 79.50 in cycle I and 88.50 in the last cycle. At the assessment of learning scenario there is an increase of 62.50 to 80.00 on cycle I and
\end{abstract}


88.33 in the last cycle. On the implementing assessment of increased 60.50 to 80.00 on cycle I and 87.22 on the last cycle. Based on the result observation it may be concluded that the implementation or (buzz group discussion) has proved to be capable of improving teachers at the elementary school 2 Karangduren in the use and use of the environment as a source for learning participants

Keyword : learning resources, buzz groud discussion

\section{PENDAHULUAN}

Selama ini kemampuan anak-anak di SD Negeri 2 Karangduren Kecamatan Pakisaji dalam menyerap pembelajaran di sekolah rata-rata masih rendah. Hal ini terbukti dengan ditunjukkan hasil evaluasi rata-rata tiap kelas masih ada sekitar 30\% anak yang memperoleh nilai di bawah KKM sekolah. Sebagai peneliti sekaligus sebagai Kepala Sekolah kami mengharapkan untuk peningkatan mutu pembelajaran siswa lebih meningkat lagi.

Salah satu strategi pembelajaran yang sesuai dengan pendekatan Pakem yang memungkinkan bisa mengembangkan kreativiats, motivasi dan partisipasi siswa dalam pembelajaran adalah dengan memanfaatkan lingkungan sekolah sebagai sumber belajar. Memanfaatkan lingkungan sekolah sebagai sumber belajar menjadi alternatif setrategi pembelajaran untuk memberikan kedekatan teoritis dan praktis bagi pengembangan hasil belajar siswa secara optimal. Ekowati (2001) mengatakan, memanfaatkan lingkungan sekolah sebagai sumber belajar merupakan bentuk pembelajaran yang berfihak pada pembelajaran melalui penggalian dan penemuan (experiencing) serta keterkaitan (relating) antara materi pelajaran dengan konteks pengalaman kehidupan nyata melalui kegiatan proyek.

Untuk mengatasi masalah yang dihadapi oleh guru di dalam kelas pada saat proses belajar mengajar, solusi yang peneliti pakai untuk meningkatkan kembali motivasi belajar siswa, salah satunya cara mengajar dengan pemanfaatan lingkungan yang ada di sekitar sekolah. Pemanfatan lingkungan sekitar sekolah dan rumah itu adalah pemanfaatan segala sesuatu yang berada di sekeliling sekolah dan rumah sebagai salah satu sumber belajar, contohnya pembelajaran tematik dalam tema lingkungan. 
Lingkungan sekolah tidak lebih hanya digunakan sebagai tempat bermain main siswa pada saat istirahat. Seperti observasi awal yang dilakukan di SD Negeri 2 Karangduren Kecamatan Pakisaji guru-guru di sekolah tersebut memanfaatkan lingkungan sekolah sebagai sumber belajar hanya satu sampai dua kali dalam satu semester itupun hanya satu atau dua orang guru saja yang melaksanakan. Guru lebih sering menyajikan pelajaran di dalam kelas walaupun materi yang disajikan berkaitan dengan lingkungan sekolah.

Sebagian besar guru mengaku enggan mengajak siswa belajar di luar kelas, karena alasan susah mengawasi. Selain itu ada guru yang menyampaikan bahwa mereka belum bisa mengatur siswa dalam memanfaatkan lingkungan sekolah sebagai sumber belajar. Untuk mengatasi hal itu perlu adanya buzz group discussion diantara para guru untuk mendiskusikan masalah pemanfaatan lingkungan sekolah sebagai sumber belajar. Dalam kegiatan diskusi tersebut para guru bisa membagi pengalaman dalam pemanfaatan lingkungan sebagai sumber belajar untuk mencapai hasil belajar yang optimal.

Dari hasil pantauan peneliti selaku Kepala Sekolah, selama ini para guru di SD Negeri 2 Karangduren Kecamatan Pakisaji masih jarang memanfaatkan lingkungan sekolah sebagai sumber belajar. Hasil kegiatan prasiklus menunjukkan bahwa semua guru belum memaksimalkan penggunaan lingkungan sekolah sebagai sumber belajar. Pada penilaian aspek skenario pembelajaran menunjukkan nilai rata-rata sebesar 62,50 dengan kriteria kurang, sedangkan hasil penilaian pada aspek pelaksanaan pembelajaran menunjukkan angka 60,56 dengan kriteria kurang.

Berdasarkan permasalahan dan latar belakang di atas maka peneliti akan melakukan sebuah penelitian tindakan kelas dengan judul : Upaya Meningkatkan Kemampuan Guru dalam Memanfaatkan Lingkungan Sekolah Sebagai Sumber Belajar Melalui Kegiatan Buzz Group Discussion di SD Negeri 2 Karangduren Kecamaan Pakisaji Semester II Tahun Pelajaran 2018/2019. 


\section{METODE PENELITIAN}

Penelitian yang digunakan adalah Penelitian Tindakan Sekolah (PTS) dan dilaksanakan dalam 2 siklus. Setiap siklus terdiri dari dua kali pertemuan. Penelitian tindakan sekolah ini dilaksanakan mengikuti pola spiral berdasarkan siklus, di mana hasil kajian melalui refleksi siklus I merupakan dasar untuk tindakan siklus II, hasil kajian melalui refleksi siklus II merupakan dasar untuk tindakan siklus selanjutnya. Langkah-langkah PTS yaitu: perencanaan, pelaksanaan, pengamatan, dan refleksi. Langkah-langkah PTS sebagaimana dijelaskan gambar 1 di bawah

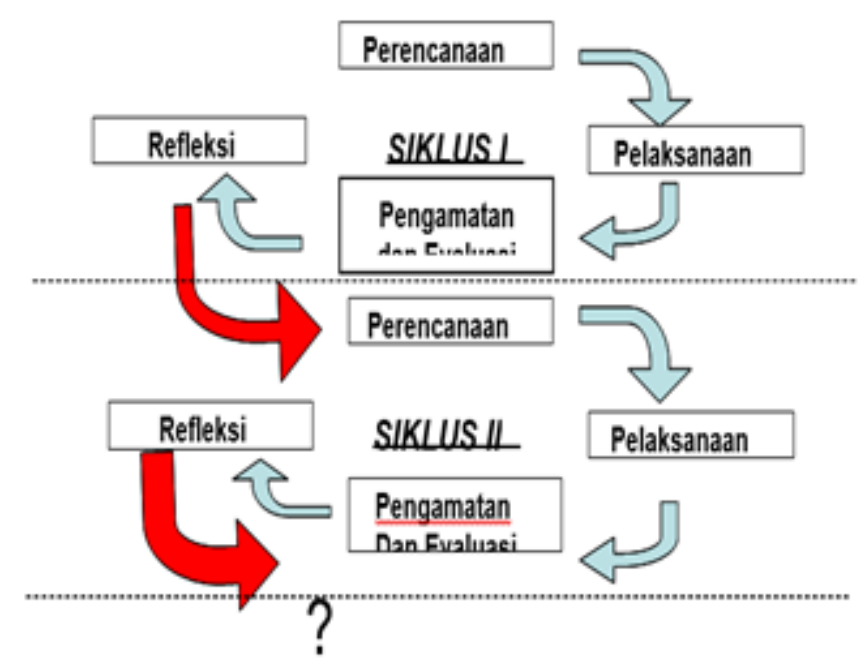

Gambar 1. Langkah PTK

Siklus PTS meliputi empat langkah yaitu: perencanaan, pelaksanaan, pengamatan dan evaluasi, serta refleksi. Masing-masing langkah dijelaskan sebagai berikut:

\section{a. Perencanaan}

Perencanaan adalah langkah awal yang dilakukan peneliti saat akan memulai tindakannya. Agar perencanaan mudah dipahami oleh peneliti yang akan melakukan tindakan, maka peneliti membuat rencana tindakan yang meliputi: Rumusan masalah yang akan dicari solusinya, Rumusan tujuan penyelesaian masalah/tujuan menghadapi tantangan/tujuan melakukan inovasi; Rumusan indikator keberhasilan pemecahan penyelesaian masalah /keberhasilan menghadapi tantangan/keberhasilan 
melakukan inovasi; Rumusan langkah-langkah kegiatan penyelesaian masalah/kegiatan menghadapi tantangan/kegiatan melakukan inovasi; Identifikasi warga sekolah dan atau pihak-pihak terkait lainnya yang terlibat dalam penyelesaian masalah/menghadapi tantangan/melakukan inovasi; Identifikasi metode pengumpulan data yang akan digunakan; Penyusunan instrumen pengamatan dan evaluasi; Penentuan waktu dan tempat pelaksanaan; Identifikasi fasilitas yang diperlukan.

\section{b. Pelaksanaan (Tindakan)}

Pelaksanaan adalah penerapan dari perencanaan. Hal-hal yang harus diperhatikan oleh peneliti adalah sebagai berikut.

Apakah ada kesesuaian antara rencana tindakan dengan pelaksanaannya?; Hal-hal apa yang dilakukan untuk menyelesaikan masalah/menghadapi tantangan/melakukan inovasi?; Bagaimana cara melaksanakan tindakan untuk memecahkan masalah/menghadapi tantangan/melakukan inovasi?; Apakah tindakan yang dilaksanakan telah terarah pada pencapaian tujuan penelitian?; Seberapa besar pelaksanaan tindakan melibatkan warga sekolah dan atau pihak-pihak terkait lainnya?;Apa peran masing-masing warga sekolah dan atau pihak-pihak terkait lainnya dalam melaksanakan tindakan?

\section{c. Pengamatan}

Pengamatan adalah pencermatan terhadap pelaksanaan tindakan. Halhal yang diamati adalah proses tindakan yang berlangsung selama tahap pelaksanaan PTS. Pengamatan menggunakan instrumen yang berisi indikator-indikator proses tindakan. Evaluasi adalah proses penetapan hasil pelaksanaan tindakan berdasarkan indikator-indikator tujuan PTS yang telah ditetapkan. Hasil evaluasi digunakan sebagai dasar untuk melakukan refleksi.

\section{d. Refleksi}

Bentuk tindakan dalam penelitian ini berupa supervisi (bimbingan kelompok) kepada guru-guru melalui diskusu kelompok kecil, agar mampu menyusun skenario pembelajaran dan pelaksanaan pembelajaran dengan 
memanfaatkan lingkungan sekolah sebagai sumber belajar secara efektif. Secara rinci bentuk tindakan dalam penelitian ini adalah :1)Menyampaikan informasi tentang pemanfaatan lingkungan sekolah sebagai sumber belajar. 2)Membimbing guru menyusun skenario pembelajaran yang berkaitan dengan pemanfaatan lingkungan sekolah sebagai sumber belajar. 3)Membimbing guru dalam memanfaatkan lingkungan sekolah sebagai sumber belajar. 4)Membimbing guru dalam melaksanakan pembelajaran dengan memanfaatkan lingkungan sekolah sebagai sumber belajar.

Sedangkan subjek penelitian tindakan sekolah ini adalah seluruh guru kelas sejumlah 6 orang guru di SD Negeri 2 Karangduren Kecamatan Pakisaji Kabupaten Malang pada semester II Tahun Pelajaran 2018/2019.

Instrumen pengumpulan data menggunakan Lembar observasi, lembaran ini terdiri atas tiga jenis yaitu lembar observasi kegiatan diskusi, penilaian skenario pembelajaran dan pelaksanaan kegiatan pembelajaran. Penelitian menggunakan lembar observasi untuk memberikan gambaran kemampuan guru dalam menyusun dan melaksanakan kegiatan pembelajaran tentang pemanfaatan lingkungan sekolah sebagai sumber belajar. Selain itu lembar observasi ini bertujuan untuk mengetahui kekurangan-kekurangan yang harus diperbaiki atau kelebihan-kelebihan yang harus dipertahankan dan ditingkatkan pada kegiatan berikutnya.

\section{HASIL DAN PEMBAHASAN}

\section{Hasil}

Dari 2 siklus penelitian yang telah dilaksanakan diperoleh hasil-hasil dari aspek yang diteliti meliputi Observasi pada Kegiatan Diskusi dalam Buzz group discussion, Penilaian Skenario Pembelajaran dan Penilaian Pelaksanaan Pembelajaran sebagaimana diuraikan di bawah ini : 


\section{a. Hasil Observasi Pada Kegiatan Diskusi}

Tabel 1. Rekapitulasi Data Hasil Observasi pada Kondisi Awal, Siklus I, dan Siklus II

\begin{tabular}{|c|c|c|c|c|c|c|c|}
\hline \multirow{3}{*}{ No } & \multirow{3}{*}{ Nama Guru } & \multicolumn{6}{|c|}{ Jumlah Skor/Siklus } \\
\hline & & \multicolumn{2}{|c|}{ Awal } & \multicolumn{2}{|r|}{$\mathrm{I}$} & \multicolumn{2}{|c|}{ II } \\
\hline & & Nilai & Kategori & Nilai & Kategori & Nilai & Kategori \\
\hline 1 & Dwi Istianik, S.Pd & 60 & $\mathrm{~K}$ & 78 & $\mathrm{C}$ & 86 & $\mathrm{~B}$ \\
\hline 2 & Zahrotus. S, S.Pd & 65 & $\mathrm{C}$ & 80 & B & 90 & $\mathrm{BS}$ \\
\hline 3 & Tri Rahayu, S.Pd & 63 & $\mathrm{~K}$ & 78 & $\mathrm{C}$ & 87 & B \\
\hline 4 & Retno Ade. H, S.Pd & 63 & $\mathrm{~K}$ & 78 & $\mathrm{C}$ & 88 & B \\
\hline 5 & M. Samsul, S.Pd & 64 & $\mathrm{~K}$ & 78 & $\mathrm{C}$ & 89 & B \\
\hline 6 & Damiati, S.Pd & 76 & $\mathrm{C}$ & 85 & B & 91 & BS \\
\hline \multicolumn{2}{|c|}{ Jumlah } & 391 & - & 477 & - & 531 & - \\
\hline \multicolumn{2}{|c|}{ Persentase } & 65,17 & $\mathrm{~K}$ & 79,50 & $\mathrm{C}$ & 88,50 & B \\
\hline
\end{tabular}

Dari penjelasan tabel di atas, maka dapat disimpulkan bahwa kemampuan guru dalam kegiatan diskusi buzz group discussion yang dilaksanakan di SD Negeri 2 Karangduren pada semester II tahun pelajaran 2018/2019 sebagai upaya peningkatan kemampuan guru dalam memberdayakan lingkungan sekolah sebagai sarana belajar terbukt berhasil. Peningkatan cukup signifikan dari kondisi awal sebesar 65,17 menjadi 79,50 dan 88,50 pada siklus terakhir.

\section{b. Hasil Penilaian Skenario Pembelajaran}

Tabel 2. Rekapitulasi Data Hasil Penilaian Skenario Pembelajaran pada Kondisi Awal, Siklus I dan Siklus II

\begin{tabular}{|c|c|c|c|c|c|c|c|}
\hline \multirow{3}{*}{ No } & \multirow{3}{*}{ Nama Guru } & \multicolumn{6}{|c|}{ Jumlah Skor/Siklus } \\
\hline & & \multicolumn{2}{|c|}{ Awal } & \multicolumn{2}{|r|}{$\mathrm{I}$} & \multicolumn{2}{|c|}{ II } \\
\hline & & Nilai & Kategori & Nilai & Kategori & Nilai & Kategori \\
\hline 1 & Dwi Istianik, S.Pd & 60 & $\mathrm{~K}$ & 85 & B & 90 & $\mathrm{BS}$ \\
\hline 2 & Zahrotus. S, S.Pd & 55 & $\mathrm{~K}$ & 75 & $\mathrm{C}$ & 85 & B \\
\hline 3 & Tri Rahayu, S.Pd & 70 & $\mathrm{C}$ & 85 & B & 90 & BS \\
\hline 4 & Retno Ade. H, S.Pd & 55 & $\mathrm{~K}$ & 80 & B & 90 & BS \\
\hline 5 & M. Samsul, S.Pd & 65 & $\mathrm{C}$ & 80 & $\mathrm{C}$ & 90 & $\mathrm{~B}$ \\
\hline 6 & Damiati, S.Pd & 70 & $\mathrm{C}$ & 75 & $\mathrm{C}$ & 85 & B \\
\hline \multicolumn{2}{|c|}{ Jumlah } & 375 & - & 480 & - & 530 & - \\
\hline \multicolumn{2}{|c|}{ Persentase } & 62,50 & $\mathrm{~K}$ & 80,00 & $\mathrm{C}$ & 88,33 & B \\
\hline
\end{tabular}

Dari penjelasan tabel di atas, maka dapat disimpulkan bahwa kemampuan guru menyusun skenario pembelajaran yang dilaksanakan di SD Negeri 2 Karangduren pada semester II tahun pelajaran 2018/2019 sebagai upaya peningkatan kemampuan guru dalam memberdayakan lingkungan sekolah sebagai sarana belajar terbukt 
berhasil. Peningkatan cukup signifikan dari kondisi awal sebesar 62,50 menjadi 80,00 dan 88,33 pada siklus terakhir.

\section{c. Hasil Penilaian Pelaksanaan Pembelajaran}

Tabel 3. Rekapitulasi Data Hasil Penilaian Pelaksanaan Pembelajaran pada Kondisi Awal, Siklus I dan Siklus II

\begin{tabular}{llllllll}
\hline \multirow{2}{*}{ No } & \multirow{2}{*}{ Nama Guru } & \multicolumn{7}{c}{ Jumlah Skor/Siklus } \\
\cline { 3 - 8 } & & \multicolumn{2}{c}{ Awal } & \multicolumn{3}{c}{ I } & \multicolumn{2}{c}{ II } \\
\cline { 3 - 7 } & & Nilai & Kategori & Nilai & Kategori & Nilai & Kategori \\
\hline 1 & Dwi Istianik, S.Pd & 66,67 & C & 86,67 & B & 90,00 & BS \\
2 & Zahrotus.S, S, Pd & 53,33 & SK & 73,33 & C & 83,33 & B \\
3 & Tri Rahayu, S.Pd & 70,00 & C & 86,67 & B & 90,00 & BS \\
4 & Retno Ade. H, S.Pd & 53,33 & SK & 73,33 & C & 83,33 & B \\
5 & M.Samsul, S.Pd & 53,33 & SK & 73,33 & C & 86,67 & B \\
6 & Damiati, S.Pd & 66,67 & C & 86,67 & B & 90,00 & BS \\
Jumlah & $\mathbf{3 6 3 , 3 3}$ & - & $\mathbf{4 8 0}$ & - & $\mathbf{5 2 3}$ & - \\
Persentase & $\mathbf{6 0 , 5 6}$ & K & $\mathbf{8 0 , 0 0}$ & C & $\mathbf{8 7 , 2 2}$ & B \\
\hline
\end{tabular}

Dari penjelasan tabel di atas, maka dapat disimpulkan bahwa kemampuan guru dalam pelaksanaan spembelajaran yang dilaksanakan di SD Negeri 2 Karangduren pada semester II tahun pelajaran 2018/2019 sebagai upaya peningkatan kemampuan guru dalam memberdayakan lingkungan sekolah sebagai sarana belajar terbukti berhasil. Peningkatan cukup signifikan dari kondisi awal sebesar 60,50 menjadi 80,00 dan 87,22 pada siklus terakhir.

\section{Pembahasan}

Lingkungan sekolah merupakan salah satu sumber belajar yang amat penting dan memiliki nilai-nilai yang sangat berharga dalam rangka proses pembelajaran siswa. Lingkungan dapat memperkaya bahan dan kegiatan belajar. Lingkungan yang dapat dimanfaatkan sebagai sumber belajar terdiri dari : (1) lingkungan sosial dan (2) lingkungan fisik (alam). Lingkungan sosial dapat digunakan untuk memperdalam ilmu-ilmu sosial dan kemanusiaan sedangkan lingkungan alam dapat digunakan untuk mempelajari tentang gejala-gejala alam dan dapat menumbuhkan kesadaran peserta didik akan cinta alam dan partispasi dalam memlihara dan melestarikan alam. 
Pemanfaatan lingkungan dapat ditempuh dengan cara melakukan kegiatan dengan membawa peserta didik ke lingkungan, seperti survey, karyawisata, berkemah, praktek lapangan dan sebagainya. Bahkan belakangan ini berkembang kegiatan pembelajaran dengan apa yang disebut out-bond, yang pada dasarnya merupakan proses pembelajaran dengan menggunakan alam terbuka.

Pemanfaatan lingkungan dapat dilakukan dengan cara membawa lingkungan kedalam kelas, seperti: membawa anak keluar dari kelas. Agar penggunaan lingkungan sebagai sumber belajar berjalan efektif, maka perlu dilakukan perencanaan, pelaksanaan dan evaluasi serta tindak lanjutnya.

Dalam rangka memperluas wawasan dan pengetahuan guru dalam berbagai hal, khususnya penguasaan substansi materi pembelajaran, penyusunan silabus, penyusunan bahan-bahan pembelajaran, strategi pembelajaran, metode pembelajaran, memaksimalkan pemakaian sarana/prasarana belajar, memanfaatkan sumber belajar, maka perlu dilakukan diskusi antara kepala sekolah sebagai pemegang kebijakan dan kendali di sekolah dengan para guru-guru untuk memanfaatkan lingkungan sekolah sebagai sumber belajar.

Dari hasil pantauan peneliti selaku kepala sekolah, selama ini para guru di SD Negeri 2 Karangduren masih sangat jarang memanfaatkan lingkungan sekolah sebagai sumber belajar. Hasil kegiatan prasiklus menunjukkan bahwa semua guru belum memaksimalkan penggunaan lingkungan sekolah sebagai sumber belajar. Pada penilaian aspek skenario pembelajaran menunjukkan nilai rata-rata sebesar 62,50 dengan kriteria kurang, sedangkan hasil penilaian pada aspek pelaksanaan pembelajaran menunjukkan angka 60,56 dengan kriteria kurang.

Sebagai upaya perbaikan maka peneliti sebagai kepala sekolah di SD Negeri 2 Karangduren berupaya meningkatkan kemampuan guru dalam menggunakan lingkungan sekitar sebagai sumber belajar dengan metode bimbingan diskusi kelompok kecil atau (buzz group discusion). Diskusi kelompok kecil (buzz group discusion) adalah sebuah kelompok besar yang berkumpul dibagi menjadi kelompok-kelompok kecil untuk mendiskusikan masalah tertentu dalam waktu yang singkat, misalnya 5 menit atau tidak lebih dari 15 menit. Sesi buzz kemudian harus ditindaklanjuti dengan diskusi utuh untuk menyimpulkan hasil temuan. 
Seorang pemimpin yang telah ditunjuk oleh masing-masing kelompok buzz melaporkan temuannya. Lalu sebuah daftar dapat dibuat dengan menggabungkan ide-ide yang berguna dari setiap kelompok menjadi sebuah kesimpulan akhir.

Upaya yang dilakukan kepala sekolah dengan menerapkan metode bimbingan diskusi kelompok kecil atau (buzz group discusion) terbukti efektif meningkatkan kemampuan guru di SD Negeri 2 Karangduren dalam menggunakan lingkungan sekitar sebagai sumber belajar. Hal tersebut dibuktikan dengan hasil penilaian pada setiap aspek penilaian yang terdiri dari aspek pengamatan diskusi kelompok kecil, aspek penyusunan aspek skenario pembelajaran dan aspek pelaksanaan pembelajaran.

Hasil penilaian ketiga aspek tersebut menunjukkan angka-angka bahwa pada aspek pengamatan diskusi kelompok kecil dari rata-rata nilai 65,17 dengan kriteria kurang, meningkat menjadi 79,50 dengan kriteria cukup dan 88,50 dengan kriteria baik pada siklus terakhir. Aspek penyusunan aspek skenario pembelajaran hasil penilaian menunjukkan angka 62,50 pada kondisi awal dengan kriteria kurang, meningkat menjadi 78,33 dengan kriteria cukup dan pada siklus terakhir menjadi 88,33 dengan kriteria baik. Aspek pelaksanaan pembelajaran dari nilai 60,56 meningkat menjadi 79,44 dan 87,22 dengan penjelasan kriteria nilai dari kurang, meningkat menjadi cukup dan baik pada siklus terakhir.

Dari hasil-hasil sebagaimana diuraikan di atas maka dapat disimpulkan bahwa pelaksanaan pembinaan dengan metode bimbingan diskusi kelompok kecil atau (buzz group discusion) terbukti mampu meningkatkan kemampuan guru-guru di SD Negeri 2 Karangduren Semester II Tahun Pelajaran 2018/2019 dalam menggunakan dan memanfaatkan lingkungan sekitar sebagai sumber belajar peserta didiknya.

\section{SIMPULAN}

Berdasarkan hasil analisis dan pembahasan siklus I dan siklus II tersebut di atas, maka dapat disimpulkan bahwa:

1. Proses pembinaan kemampuan guru dalam menggunakan lingkungan sebagai sumber belajar di SD Negeri 2 Karangduren Kecamatan Pakisaji melalui 
pelaksanaan diskusi kelompok kecil (buzz group discusion) terbukti dapat meningkatkan kemampuan menggunakan lingkungan sebagai sumber belajar. Hal tersebut dibuktikan dengan meningkatnya hasil penilaian terhadap ke tiga aspek yang menjadi fokus perbaikan yaitu aspek pengamatan diskusi kelompok kecil, aspek penyusunan aspek skenario pembelajaran dan aspek pelaksanaan pembelajaran.

2. Hasil penilaian ketiga aspek tersebut menunjukkan angka-angka bahwa pada aspek pengamatan diskusi kelompok kecil dari rata-rata nilai 64,17 dengan kriteria kurang, meningkat menjadi 79,00 dengan kriteria cukup dan 88,17 dengan kriteria baik pada siklus terakhir. Aspek penyusunan aspek skenario pembelajaran hasil penilaian menunjukkan angka 61,67 pada kondisi awal dengan kriteria kurang, meningkat menjadi 79,17 dengan kriteria cukup dan pada siklus terakhir menjadi 86,67 dengan kriteria baik. Aspek pelaksanaan pembelajaran dari nilai 60, meningkat menjadi 79,44 dan 86,11 dengan penjelasan kriteria nilai dari kurang, meningkat menjadi cukup dan baik pada siklus terakhir.

Dari perolehan hasil penelitian sebagaimana dijelaskan di atas maka dapat disimpulkan bahwa pelaksanaan penelitian dinyatakan berhasil, karena semua komponen yang diteliti menunjukkan hasil di atas kriteria keberhasilan sebesar $85 \%$.

\section{REFERENSI}

Akbar, Setiady P., Usman H., 1995, Metodologi Penelitian Sosial, Jakarta : Penerbit PT. Bumi Aksara

Amir Hamzah Suleiman. 1981. Media Audio Visual untuk Pengajaran, Penerangan, dan Penyuluhan. Jakarta : PT. Gramedia

Arikunto. S. 1982. Prosedur Penelitian Suatu Pendekatan Praktek, Jakarta'. Bina. Aksara..

As'ari, Abdurrahman. 2003. Pembelajar Matematika Dengan Kooperatif Learning. Malang

Badru Zaman, dkk. 2005. Media dan Sumber Belajar TK. Buku Materi Pokok PGTK 2304. Modul 1-9. Jakarta Universiats Terbuka.

Moleong, Lexy J. 2008 Metodologi Penelitian Kualitatif, Penerbit PT Remaja Rosdakarya 
Callahan, Joseph F. \& Clark, Leonard H. 1982. Teaching in the Middle and Secondary Schools. New York: Macmilland Publishing Co. Inc.

Conny Semiawan dkk. 1989 Pendekatan Keterampilan Proses, Penerbit PT. Gramedia, Jakarta

Danim, Sudarwan, 1994, Tranformasi Sumber Daya Manusia, Bumi Aksara, Jakarta.

Dewa Ketut Sukardi dan Desak Nila Kusmawati. 2008. Proses Bimbingan dan Konseling di Sekolah. Jakarta: Rineka Cipta.

Djamarah, Syaiful Bahri, 1994, Prestasi Belajar dan Kompetensi Guru, Usaha Nasional, Surabaya.

Eko Hari Sutopo 2009.. Metodologi Penelitian Kualitatif. Surakarta: UNS Press.

Gulley, Halbert E. 1960. Discussion, Conference, and Group Process. University of Illionis.

Hamzah B. Uno. 2011. Teori Motivasi dan Pengukurannya: Analisis di Bidang Pendidikan. Jakarta: Bumi aksara

Imron, Ali, 1995, Pembinaan Guru di Indonesia, Pustaka Jaya, Jakarta.

J. Moleong, Lexy. 1989.Metodologi Penelitian. Kualitatif. Bandung: Remadja Karya

Kamil Pasya Gurniwan, 2010.Kapita Selekta Sosiologi dan Antropologi, Buana Nusa, Bandung

Nasution, S.. 1996. Metode Penelitian Naturalistik-Kualitatif. Bandung : Tarsito.

Pratita Ruwahidha Nur Ichsan. 2010.Peningkatan Motivasi Karir Melalui Teknik Diskusi Kelompok Kecil Buzz Group Discussion Pada Siswa SMK Muhammadiyah 1 Tempel. Skripsi. FIP-UNY.

Roestiyah, NK, 1986, Masalah-masalah Ilmu Keguruan, Bina Aksara, Jakarta.

Rusyan Tabrani. 2001. Pendekatan dalam Proses Belajar Mengajar. Bandung Remaja Rosdakarya.

Samana, A. 1994. Profesionalisme Keguruan, Kanisius, Yogyakarta.

Sardiman, AM, 1986, Interaksi dan Motivasi Belajar Mengajar, CV. Rajawali, Jakarta.

Soetjipto. 1999. Profesi Keguruan, Jakarta:Rineka Cipta.

Sudjana, Nana, 1989, Dasar-dasar Proses Belajar Mengajar, Sinar Baru Algensindo, Bandung.

Sudjana. 2005. Metode statistika. Tarsito. Bandung.

Sugihartono dkk. 2012. Psikologi Pendidikan. Yogyakarta: UNY Press

Tohirin, 2007. Bimbingan dan Konseling Di Sekolah : PT Grafindo Persada. Jakarta.

Wijaya, H. ES dan Tabrani Rusyan, 1992, Profesionalisme Tenaga Kependidikan, Nine Karya Jaya, Bandung. 